\title{
The Prediction of Carbon Dioxide-Crude Oil Minimum Miscibility Pressure by CMG
}

\author{
Taoping Chen ${ }^{a}$, Qianwei Zhang ${ }^{\mathrm{b}}$ and Bin Zhao ${ }^{\mathrm{c}}$ \\ The Key Laboratory of Enhancing Oil and Gas Recovery Efficiency of Educational Ministry, Northeast \\ Petroleum University, Daqing, Heilongjiang, 163318, China \\ actp010@163.com, b2448950836@qq.com, c244802970@qq.com
}

Keywords: CMG, component model, carbon dioxide, minimum miscibility pressure.

\begin{abstract}
According to the PVT high pressure physical parameters of oil and gas, Using the PVTI in reservoir numerical simulation software Eclipse to determine the phase characteristics of the fluid, fitting the basic parameters and building component model, using the GEM modular program of CMG to calculate the oil displacement efficiency under different inject pressure, according to oil displacement efficiency and injection pressure relationship curve presents two lines before and after the inflection point, regressing the equation of two lines, and the intersection of the pressure be determined the minimum miscibility pressure of carbon dioxide-crude oil; in order to confirm the results, at the same time using slim tube experiment method and empirical formula methods to determine the minimum miscibility pressure of carbon dioxide-crude oil, and the slim tube experiment should be treated as the reference standard, Calculating the relative error of CMG method and the empirical formula method which are compared with the measured value of slim tube method. The results show that when the reservoir temperature are $90^{\circ} \mathrm{C}$ and $108^{\circ} \mathrm{C}$, the carbon dioxide-crude oil minimum miscibility pressure of Shu 101 block in Yushulin oilfield is predicted by CMG, comparing with measured value of slim tube method, the relative error are $1.54 \%$ and $0.72 \%$, the average relative error is $1.13 \%$, which is less than the commonly used empirical formula of relative error average value, showing that carbon dioxide-oil minimum miscibility pressure is accurate and reliable by CMG.
\end{abstract}

\section{Introduction}

The minimum miscibility pressure is an important parameter to determine whether the gas achieves miscible displacement. The current methods of determining minimum miscibility pressure include the slim tube experiment[1-2], state equation method[3], interfacial tension disappearing method[4], empirical formula method[5] and so on. The slim tube experiment is a common method to determine the minimum miscibility pressure, its reliability is high, but the experimental time is long. The state equation method combines the minimum miscibility pressure with the changes of system phase, calculating bubble point of carbon dioxide and crude oil system, choosing the mixed phase function as the basis of judgment, finally obtains the minimum miscibility pressure, but the method of insufficient is difficult to determine the critical value of heavy constituent. The interfacial tension method is not possible to determine the interfacial tension of 0 , only to see the miscible state when the interfacial tension changes to 0 , thus using the extrapolation method to calculate the minimum miscibility pressure exists large relative error when the interfacial tension is 0 . Different empirical formulas relate to different physical parameters of oil and gas, applicable to different reservoir conditions, the minimum miscibility pressure be calculated for a specific reservoir varies greatly, and it needs to be selected after comparative analysis in practice. Wherefore, people hope to get a method with accurate predication results, less manpower and material consumption, and a wide range of application. Therefore, this paper is based on the PVT parameters of oil and gas, establishing the compositional model, using the CMG to calculate the oil displacement efficiency of carbon dioxide in different injection pressure, thus determining the minimum miscibility pressure of carbon dioxide-crude oil, In order to provide theoretical basis for oil field test and application. 


\section{The Core Conceptual Model}

In order to facilitate the application of CMG reservoir numerical simulation software to predict the carbon dioxide-oil minimum miscibility pressure, building a $1 \times 1 \times 5000$ single porosity grid system which single grid size is $0.045 \mathrm{~m} \times 0.045 \mathrm{~m} \times 0.008 \mathrm{~m}$ for the homogeneous core which size is $0.045 \mathrm{~m} \times 0.045 \mathrm{~m} \times 40 \mathrm{~m}$ by CMG. Referring to the reservoir parameters of Shu 101 block in Yushulin oilfield, the permeability of homogeneous conceptual model is $1.06 \times 10^{-3} \mu^{2}$, and porosity is $10.65 \%$. 1 injection well and 1 production well are arranged in the grid at both ends of the conceptual model respectively. The homogeneous core concept model mesh is shown in Fig. 1.

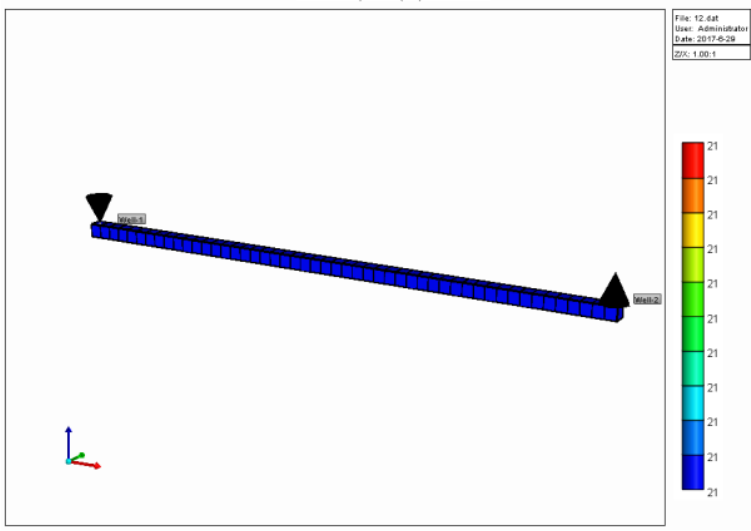

Fig. 1 Sketch map of homogeneous core conceptual model mesh generation

\section{Fluid and Rock Parameters}

According to the basic parameters of the experimental measured that all numbers are from Shu 101 block in Yushulin oilfield, including fluid and rock parameters (Table 1,2) and fluid component analysis results, using PVTI in the oil numerical simulation software Eclipse to divide the pseudo-component of fluid in reservoir (Table 3), in order to establish the component model.

Table 1 The formation water property basic parameters from Shu 101 well in Yushulin oilfield

\begin{tabular}{|c|c|c|c|}
\hline $\begin{array}{c}\text { Reference Pressure } \\
(\mathrm{MPa})\end{array}$ & $\begin{array}{c}\text { Compression } \\
\text { coefficient } \\
\left(\mathrm{MPa}^{-1}\right)\end{array}$ & $\begin{array}{c}\text { Volumetric coefficient } \\
\left(\mathrm{rm}^{3} / \mathrm{sm}^{3}\right)\end{array}$ & $\begin{array}{c}\text { Viscosity } \\
(\mathrm{mPa} \cdot \mathrm{s})\end{array}$ \\
\hline 22.5 & $3.03 \mathrm{E}-4$ & 1.104 & 0.6 \\
\hline
\end{tabular}

Table 2 The basic parameters of rock and Ground fluid from Shu 101 well in Yushulin oilfield

\begin{tabular}{|c|c|c|c|c|}
\hline \multicolumn{2}{|c|}{ Rock parameters } & \multicolumn{3}{c|}{ Ground fluid density } \\
\hline $\begin{array}{c}\text { Reference pressure } \\
(\mathrm{MPa})\end{array}$ & $\begin{array}{c}\text { Compression coefficient } \\
\left(\mathrm{MPa}^{-1}\right)\end{array}$ & $\begin{array}{c}\text { Oil density } \\
\left(\mathrm{kg} / \mathrm{m}^{3}\right)\end{array}$ & $\begin{array}{c}\text { Water density } \\
\left(\mathrm{kg} / \mathrm{m}^{3}\right)\end{array}$ & $\begin{array}{c}\text { Gas density } \\
\left(\mathrm{kg} / \mathrm{m}^{3}\right)\end{array}$ \\
\hline 22.05 & $88.4 \mathrm{E}-4$ & 855.4 & 1000 & 0.6 \\
\hline
\end{tabular}

Table 3 Pseudo-component classification of Shu 101 block in Yushulin oilfield

\begin{tabular}{|c|c|c|c|}
\hline Component & Mole fraction (\%) & Quality score (\%) & Molar mass \\
\hline $\mathrm{N}_{2}$ & 0.2 & 0.02959 & 28.013 \\
\hline $\mathrm{CO}_{2}$ & 0.1 & 0.02324 & 44.01 \\
\hline $\mathrm{C} 1$ & 20.91 & 1.77154 & 16.043 \\
\hline $\mathrm{C} 2-\mathrm{C} 4$ & 3.56 & 0.74688 & 39.839 \\
\hline $\mathrm{C} 5-\mathrm{C} 6$ & 0.25 & 0.09863 & 74.707 \\
\hline $\mathrm{C} 7-\mathrm{C} 8$ & 0.94 & 0.53116 & 107 \\
\hline $\mathrm{C} 9-\mathrm{C} 11$ & 7.19 & 5.27328 & 138.88 \\
\hline $\mathrm{C} 12-\mathrm{C} 16$ & 21.68 & 21.0137 & 183.54 \\
\hline $\mathrm{C} 17-\mathrm{C} 21$ & 20.83 & 27.2717 & 247.92 \\
\hline $\mathrm{C} 22+$ & 24.34 & 43.2403 & 336.4 \\
\hline
\end{tabular}




\section{Calculation Results and Analysis}

In $40 \mathrm{~m}$ long core models, setting reservoir temperature are $90{ }^{\circ} \mathrm{C}$ and $108{ }^{\circ} \mathrm{C}$, to control the displacement pressure gradient in $0.02 \mathrm{MPa} / \mathrm{m}$, through changing different injection pressure to get different oil displacement efficiency, drawing the relationship curve of oil displacement efficiency and injection pressure, as shown in Fig. 2 and Fig. 3.

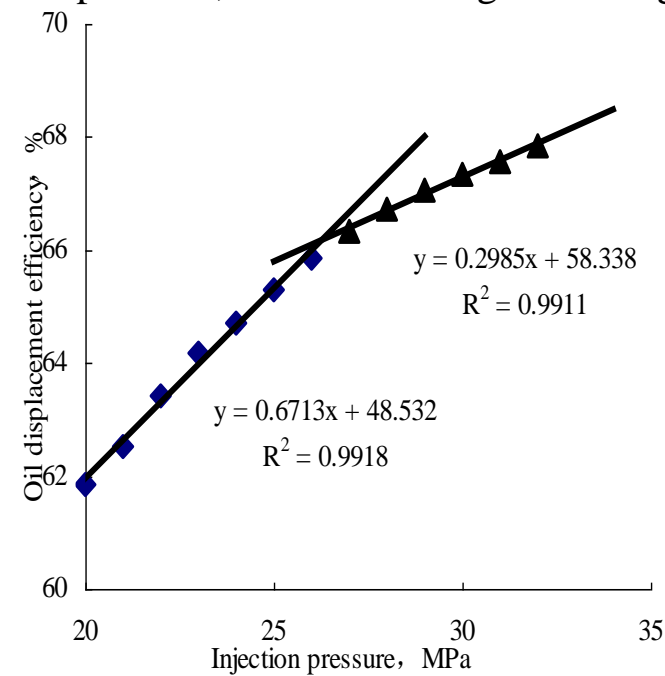

Fig. 2 Relation curve of oil displacement efficiency and injection pressure $\left(90^{\circ} \mathrm{C}\right)$

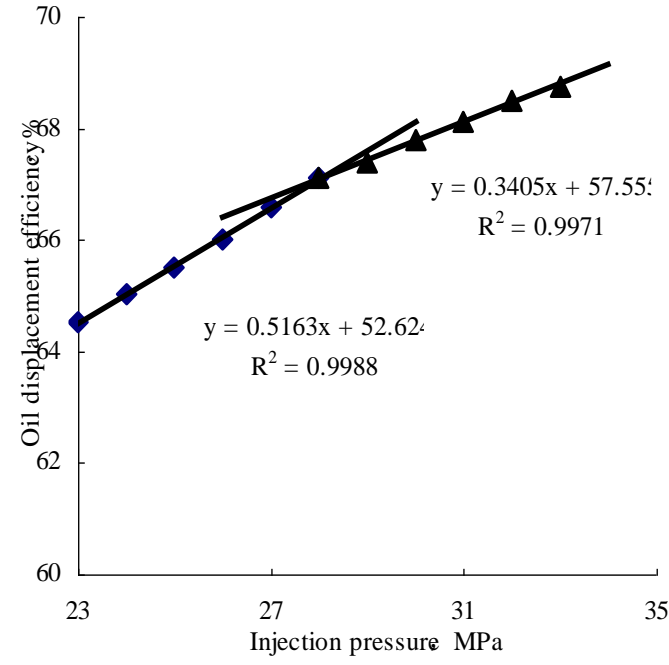

Fig. 3 Relation curve of oil displacement efficiency and injection pressure $\left(108^{\circ} \mathrm{C}\right)$

By the Fig. 2 shows: When the reservoir temperature is $90^{\circ} \mathrm{C}$, the oil displacement efficiency of carbon dioxide increases with the increasing of injection pressure, and reaching a certain pressure oil displacement efficiency curve appeared inflection point, after reaching the inflection point, the increase range of displacement efficiency decreases with the increase of injection pressure. The reason of this, Before reaching the minimum miscibility pressure, carbon dioxide is the gas phase, and the carbon dioxide has a higher oil-draining ratio, so the increase range of displacement efficiency with the increase of injection pressure is greater; When the injection pressure results in that carbon dioxide miscibility with crude oil, the oil displacement efficiency of carbon dioxide gas increased, but oil-draining ratio drops rapidly ${ }^{[6]}$, so when the injection pressure is higher than the minimum miscibility pressure, the increase range of oil displacement efficiency decreases with the increase of injection pressure.

Before and after the inflection point of oil displacement efficiency and injection pressure figure, the figure of oil displacement efficiency and injection pressure appears two straight lines, and the determination coefficient $\mathrm{R}^{2}$ of this two regression straight lines are 0.9918 and 0.9911 , shows that the degree of fitting is very good, the intersection point for the two equation is $26.3 \mathrm{MPa}$, which is the minimum miscibility pressure of carbon dioxide-crude oil at $90^{\circ} \mathrm{C}$.

By the Fig. 3 shows: when the reservoir temperature is $108^{\circ} \mathrm{C}$, the trend of the oil displacement efficiency figure of the carbon dioxide is similar to the figure of $90^{\circ} \mathrm{C}$, and two regression straight lines of determination coefficient $\mathrm{R}^{2}$ are 0.9988 and 0.9971 , shows that the degree of fitting is pretty good, In the same way the minimum miscibility pressure of $108^{\circ} \mathrm{C}$ can be calculated, which pressure is 28.0 MPa.

Seeing from calculation results, when the reservoir temperature is $108^{\circ} \mathrm{C}$, the minimum miscibility pressure of carbon dioxide-crude oil is greater than that of the reservoir temperature is $90^{\circ} \mathrm{C}$, and the reason of this: when it has a certain oil and gas component, as the temperature increases, carbon dioxide is more difficult to dissolve in oil, the solubility of carbon dioxide in crude oil is reduced, which resulted in the minimum miscibility pressure of carbon dioxide-crude oil increased. 


\section{Experimental Confirmation and Comparative Analysis}

In order to confirm the accuracy that the numerical reservoir simulation software CMG prediction of carbon dioxide-crude oil minimum miscibility pressure, in the same components of oil and gas and the same reservoir temperature conditions, this paper selected the slim tube experiment method and empirical formula methods to determine the minimum miscibility pressure of carbon dioxide-crude oil, and the slim tube experiment is treated as the reference standard. Calculating relative errors of CMG method and empirical formula method, which compared with the number of the slim tube experiment.

\subsection{The Minimum Miscibility Pressure Was Measured by Slim Tube Experiment}

The main equipments used in the slim tube experiment are injection pump, intermediate container, filter, pressure transducer, observation window, pressure controller, liquid fraction collector and gas meter. The main experimental materials are slim tube model (diameter $4 \mathrm{~mm}$, length $43 \mathrm{~m}$, permeability $6.2465 \times 10^{-3} \mu \mathrm{m}^{2}$, porosity $37.35 \%$ ), Yushulin oilfield simulated oil and bottled carbon dioxide .

In the process of experiment, the simulated reservoir temperature are $90^{\circ} \mathrm{C}$ and $108^{\circ} \mathrm{C}$, by changing the injection pressure, measured the oil displacement efficiency of different pressure, according to the results of oil displacement experiment to draw the relation curve of oil displacement efficiency and injection pressure when it's reservoir temperature is $90^{\circ} \mathrm{C}$ as shown in Fig. 4, and the relation curve of oil displacement efficiency and injection pressure when it's reservoir temperature is $108^{\circ} \mathrm{C}$ as shown in Fig. 5.

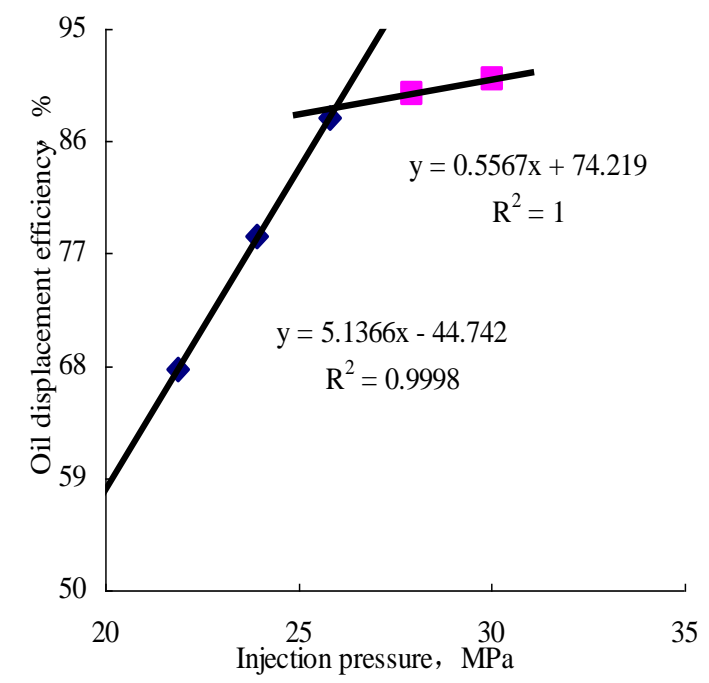

Fig. 4 Relation curve of oil displacement efficiency and injection pressure $\left(90^{\circ} \mathrm{C}\right)$

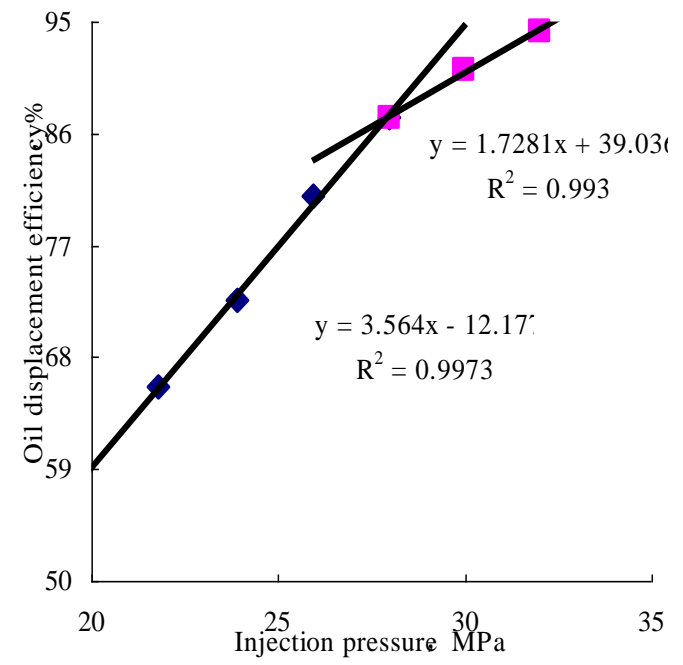

Fig. 5 Relation curve of oil displacement efficiency and injection pressure $\left(108^{\circ} \mathrm{C}\right)$

By the Fig. 4 shows: When the reservoir temperature is $90^{\circ} \mathrm{C}$, the oil displacement efficiency of carbon dioxide increases with the increase of injection pressure, and reaches a certain pressure oil displacement efficiency curve appeared inflection point, after reaching the inflection point, the increase range of displacement efficiency decreases with the increase of injection pressure. Two regression straight lines of determination coefficient $\mathrm{R}^{2}$ are 0.9998 and 1 , shows that the degree of fitting is very good, the intersection point for the two equation is $25.9 \mathrm{MPa}$, which is the minimum miscibility pressure of carbon dioxide-crude oil at $90^{\circ} \mathrm{C}$.

By the Fig. 5 shows: when the reservoir temperature is $108^{\circ} \mathrm{C}$, the trend of the oil displacement efficiency figure of the carbon dioxide is similar to the figure of $90^{\circ} \mathrm{C}$, and two regression straight lines of determination coefficient $\mathrm{R}^{2}$ are 0.9973 and 0.993 , shows that the degree of fitting is very good, In the same way the minimum miscibility pressure of $108^{\circ} \mathrm{C}$ can be calculated, which pressure is 27.8MPa.

When the reservoir temperature are $90^{\circ} \mathrm{C}$ and $108^{\circ} \mathrm{C}$, The use of $\mathrm{CMG}$ calculated the carbon dioxide-crude oil minimum miscibility pressure respectively were $26.3 \mathrm{MPa}$ and 28.0MPa, the relative 
error compared with the slim tube experiment method were $1.54 \%$ and $0.72 \%$, the average is $1.13 \%$ (Table 4).

\subsection{The Minimum Miscibility Pressure Was Calculated by Empirical Formula Method}

In order to compare the calculated results of $\mathrm{CMG}$, In this paper, the minimum miscibility pressure of carbon dioxide crude oil at $90^{\circ} \mathrm{C}$ and $108^{\circ} \mathrm{C}$ are calculated by using some commonly used empirical formulas. The calculated results of different empirical formulas are shown in table 4.

Because each formula relates to oil and gas physical properties are different, some not included the composition of crude oil, some not related to the distribution of molecular weight, but the molecular weight distribution has great influence on the minimum miscibility pressure, causing the calculation of carbon dioxide-oil minimum miscibility pressure will has some differences with the actual measured value ${ }^{[7]}$.

Table 4 The prediction of minimum miscibility pressure and relative error by different methods

\begin{tabular}{|c|c|c|c|c|c|c|}
\hline \multirow{2}{*}{\multicolumn{2}{|c|}{ Prediction methods }} & \multicolumn{2}{|c|}{$\begin{array}{c}\text { Minimum } \\
\text { Miscibility } \\
\text { Pressure(MPa) }\end{array}$} & \multicolumn{3}{|c|}{$\begin{array}{c}\text { Relative error } \\
(\%)\end{array}$} \\
\hline & & $90^{\circ} \mathrm{C}$ & $108^{\circ} \mathrm{C}$ & $90^{\circ} \mathrm{C}$ & $108^{\circ} \mathrm{C}$ & Average \\
\hline \multicolumn{2}{|c|}{ Slim tube experiment } & 25.9 & 27.8 & - & - & - \\
\hline \multicolumn{2}{|c|}{$\mathrm{CMG}$} & 26.3 & 28.0 & 1.54 & 0.72 & 1.13 \\
\hline \multirow{7}{*}{$\begin{array}{l}\text { Empirical } \\
\text { formula } \\
\text { methods }\end{array}$} & $\mathrm{N} \mathrm{PC}$ & 29.99 & 31.03 & 16.69 & 11.62 & 14.15 \\
\hline & Glas $\varnothing$ & 35.63 & 39.25 & 38.66 & 41.19 & 39.92 \\
\hline & American Petroleum Institute & 31.079 & 29.30 & 20.93 & 5.40 & 13.16 \\
\hline & Cronquist & 26.43 & 31 & 2.84 & 11.51 & 7.17 \\
\hline & Emera-Sarma & 25.57 & 25.34 & 0.51 & 8.85 & 4.68 \\
\hline & Yuan & 34.688 & 41.53 & 34.97 & 49.39 & 42.18 \\
\hline & Silva & 24.65 & 27.1 & 4.09 & 2.52 & 3.30 \\
\hline
\end{tabular}

By the table 4 shows, the Silva method and the Emera- Sarma method take the distribution of crude oil components into account and the relative error of the calculated results are smaller, while the average values of other empirical formulas are greater than 5\%. When the reservoir temperature are $90^{\circ} \mathrm{C}$ and $108^{\circ} \mathrm{C}$, Calculating the minimum miscibility pressure by Silva method, which number are $24.65 \mathrm{MPa}$ and $27.1 \mathrm{MPa}$, compared with the slim tube experiment method the relative error of Silva method are $4.09 \%$ and $2.5 \%$, the average relative error is $3.30 \%$. When the reservoir temperature are $90^{\circ} \mathrm{C}$ and $108{ }^{\circ} \mathrm{C}$, Calculating the minimum miscibility pressure by Emera- Sarma method, which number are are $25.57 \mathrm{MPa}$ and $25.34 \mathrm{MPa}$, compared with the slim tube experiment method the relative error of Emera- Sarma method are $0.51 \%$ and $8.85 \%$, the average relative error is $4.68 \%$. When the reservoir temperature are $90{ }^{\circ} \mathrm{C}$ and $108{ }^{\circ} \mathrm{C}$, Calculating the minimum miscibility pressure by $\mathrm{CMG}$, which number a are 26.3MPa and 28.0 MPa, compared with the slim tube experiment method the relative error of $\mathrm{CMG}$ are $1.54 \%$ and $0.72 \%$, the average relative error is $1.13 \%$. Thus, the relative error of calculation results by using CMG is smallest.

\section{Conclusion}

(1) In this paper, the prediction value of the minimum miscibility pressure of Shu 101 block in Yushulin oilfield are $26.3 \mathrm{MPa}$ and $28.0 \mathrm{MPa}$ respectively by reservoir numerical simulation software CMG, when the reservoir temperature are $90^{\circ} \mathrm{C}$ and $108^{\circ} \mathrm{C}$.

(2) When the reservoir temperature are $90^{\circ} \mathrm{C}$ and $108^{\circ} \mathrm{C}$, the relative error are $1.54 \%$ and $0.72 \%$ respectively by $\mathrm{CMG}$, the average relative error is $1.13 \%$, compared with the slim tube experiment method, and Silva method and Emera-Sarma method's average relative error is smaller in the all commonly used empirical formula methods, their average relative error are $3.30 \%$ and $4.68 \%$ respectively, which shows that the prediction of carbon dioxide-crude oil minimum miscibility pressure by $\mathrm{CMG}$ is accurate and reliable. 


\section{Acknowledgements}

The 13th Five-Year national major projects (2017ZX05009004-005)"Feasibility study of composite gas to improve $\mathrm{CO}_{2}$ gas flooding in low permeability-extra low permeability reservoir"

\section{References}

[1]. Xiangliang Li, Ping Guo, Huanchen Li, et al. Determination of Minimum Miscibility Pressure Between Formation Oil and Carbon Dioxide in Fan 124 Block,Da Lu Oilfield [J]. Petroleum Geology and Recovery Efficency. Vol. 9 (2002) No. 6, p. 62-64.

[2]. Xuefeng Yang, Ping Guo, Zhimin. Du. Influence Factors Appraisal of Slim-Tube Simulation to Determine The Minimum Miscibility Pressure [J]. Journal of Southwest Petroleum Institute. Vol. 26 (2004) No.3, p. 41-55.

[3]. Yeheng Sun, Guangzhong Lv, Yanfang Wang, Aiqi Dong. The Equation of State Method For Determining The Minimum Miscibility Pressure of $\mathrm{CO}_{2}[\mathrm{~J}]$. Petroleum Geology and Recovery Efficiency. Vol. 13 (2006) No.1, p. 82-84.

[4]. Baozhai Peng,Hu Luo, Guangjin Chen, et al. Determination of The Minimum Miscibility Pressure of $\mathrm{CO}_{2}$ and Crude Oil System by Vanishing Interfacial Tension Method [J]. Acta Petrolei Sinica, Vol. 28 (2007) No.3 , p. 93-95.

[5]. Anping Ye. Experience Formula of Determining Minimum Miscible Pressure In $\mathrm{CO}_{2}$ Flooding [J]. Fault-Block Oil \& Gas Field, Vol. 16 (2009) No.5 , p. 75-76.

[6]. Xingliang Li. Experimental Study on The Effect of Temperature and Injection Pressure On $\mathrm{CO}_{2}$ Flooding [J]. Petroleum Geology and Recovery Efficiency, Vol. 22 (2015) No.1 , p. 84-87.

[7]. Zhenquan LI. Gas Flooding Enhanced Oil Recovery Technology Research and Field Test [M]. Petroleum Industry Press, 2004. 